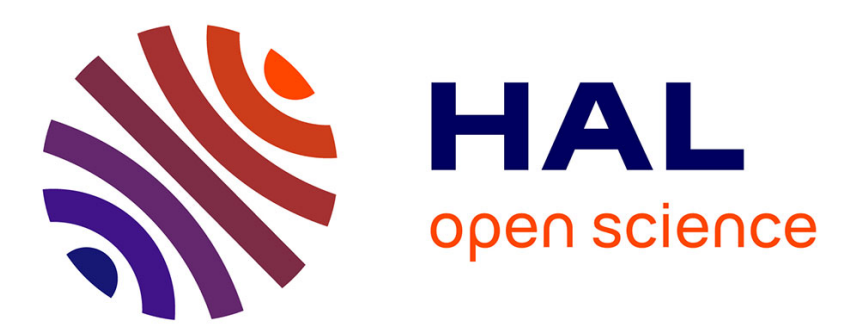

\title{
Diversity of greenhouse gas emission drivers across European countries since the 2008 crisis
}

\author{
Quentin Perrier, Céline Guivarch, Olivier Boucher
}

\section{To cite this version:}

Quentin Perrier, Céline Guivarch, Olivier Boucher. Diversity of greenhouse gas emission drivers across European countries since the 2008 crisis. Climate Policy, 2019, pp.1-21. 10.1080/14693062.2019.1625744 . halshs-02161008

\section{HAL Id: halshs-02161008 \\ https://shs.hal.science/halshs-02161008}

Submitted on 20 Jun 2019

HAL is a multi-disciplinary open access archive for the deposit and dissemination of scientific research documents, whether they are published or not. The documents may come from teaching and research institutions in France or abroad, or from public or private research centers.
L'archive ouverte pluridisciplinaire HAL, est destinée au dépôt et à la diffusion de documents scientifiques de niveau recherche, publiés ou non, émanant des établissements d'enseignement et de recherche français ou étrangers, des laboratoires publics ou privés. 


\title{
Diversity of greenhouse gas emission drivers across European countries since the 2008 crisis
}

\author{
Quentin Perrier ${ }^{\mathrm{a}, *}$, Céline Guivarch ${ }^{\mathrm{b}}$, Olivier Boucher ${ }^{\mathrm{c}}$ \\ ${ }^{a}$ Institut Pierre-Simon Laplace, Sorbonne Université / CNRS, Paris \\ ${ }^{b}$ Centre international de recherche sur l'environnement et le développement, Ecole des Ponts Paris \\ Tech, Champs-sur-Marne \\ ${ }^{c}$ Institut Pierre-Simon Laplace, Sorbonne Université / CNRS, Paris
}

\begin{abstract}
In the context of climate change mitigation and the Paris Agreement, it is critical to monitor and understand the dynamics of greenhouse gas emissions over different regions of the world. In this study, we quantify the contributions of different drivers behind the observed emission decrease in Europe between 2009 and 2014. To this end, we build a novel dataset of deflated input-output tables for each of the $28 \mathrm{EU}$ countries. This dataset enables us to conduct the first Structural Decomposition Analysis of emissions in European countries since the economic crisis. Our results show that the largest drivers of emissions have been the improvement in carbon intensity $\left(-394 \mathrm{MtCO}_{2} \mathrm{e}\right)$, largely offset by the economic recovery $\left(+285 \mathrm{MtCO}_{2} \mathrm{e}\right)$. However, other less intuitive drivers also played a significant role in the emission decline: changes in the production system $\left(-104 \mathrm{MtCO}_{2} \mathrm{e}\right)$, mostly driven by an increase in imports; the evolution of final demand patterns $\left(-101 \mathrm{MtCO}_{2} \mathrm{e}\right)$; a decrease in emissions due to household heating $\left(-83 \mathrm{MtCO}_{2} \mathrm{e}\right)$ and private transport $\left(-24 \mathrm{MtCO}_{2} \mathrm{e}\right)$, with a small offset from population growth $\left(+39 \mathrm{MtCO}_{2} \mathrm{e}\right)$. However, these aggregate figures mask significant variations between EU countries which we also document. This study highlights the importance of including changes in consumption patterns, trade and temperature anomalies in tracking and fostering progress towards the Paris Agreement goals.
\end{abstract}

Keywords: GHG emissions; Structural decomposition analysis; European Union.

JEL Classification: O13 - Q40 - Q54 - Q58

\section{Highlights}

- The largest drivers of EU greenhouse gas emissions changes between 2009 and 2014 have been improved carbon intensity and economic recovery.

\footnotetext{
${ }^{*}$ Corresponding author. Tel.: +33663246813

Email addresses: perrier@centre-cired.fr (Quentin Perrier), guivarch@centre-cired.fr (Céline Guivarch), olivier.boucher@ipsl.fr (Olivier Boucher)
} 
- Changes in imports, production technologies, consumption patterns and household heating also played a significant role.

- Dynamics of change varied significantly from one country to another.

- Tracking these drivers is essential to monitor progress towards the Paris Agreement goals and increase ambition. 


\section{Introduction}

The Paris Agreement has set a goal of limiting the global temperature increase to $2^{\circ} \mathrm{C}$, and if possible $1.5^{\circ} \mathrm{C}$. A major challenge is now to ramp up mitigation policies and overcome barriers to decarbonization of the world's economy. To this end, it is critical to understand the drivers behind the observed evolution of emissions. Only in this way can progress be assessed and policies evaluated - while taking into account regional and country-level specificities.

In its Article 4.1, the Paris Agreement also stresses the need to reach an emission peak as soon as possible, and then to achieve greenhouse gas neutrality. As such, the European Union is a particularly interesting case to study, since it is one of the first regions in the world where a greenhouse gas (GHG) emission peak may have already occurred (figure 1a).

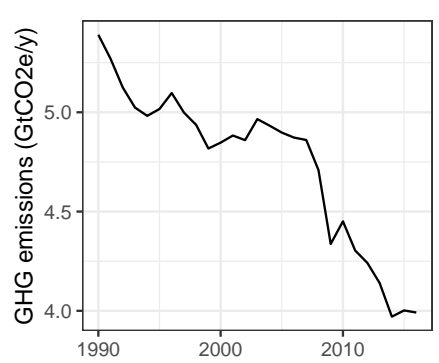

(a) Evolution of EU greenhouse gas emissions over the period 1990-2017

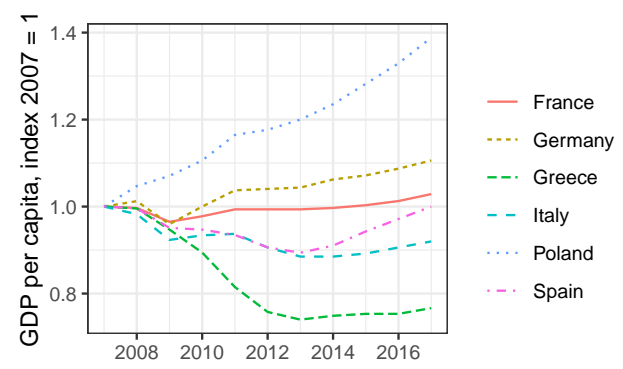

(b) GDP per capita relative to 2007 , for six European countries, over the period 2007-2017

Figure 1: EU emissions and GDP per capita in six European countries. Source: Eurostat

In addition, the 28 Member States of the European Union offer a rich panorama because of the diversity of national dynamics, in economic, demographic and political terms. Since the economic crisis of 2008, the economic recovery has been fast in Poland, while Greece has experienced a prolonged recession. Between these two extremes, the other Member States have eventually returned to growth, but after a more or less prolonged period of recession (figure 1b). This economic crisis is likely to have generated transformations in production systems by affecting certain sectors more than others, as well as by inducing changes in both public and private consumption. Economic and fiscal adjustments have also had an impact on the evolution of current accounts, with an improvement for a majority of countries, and therefore a decrease in imports relative to exports. There are also contrasted demographic trends (figure 5 in appendix), resulting from variations in the evolution of birth and death rates and migration patterns over this period.

As energy remains a sovereign prerogative, each of the 28 Member States has put in place its own energy and climate policy under an overarching European goal. The German Energiewende with the exit of nuclear power, the Spanish Sostenibilidad Energética with a sudden end to support tariffs for renewable energy in 2012, or the Climate Change Bill in the United Kingdom with the introduction of a $\mathrm{CO}_{2}$ floor price are examples of 
this diversity in policies.

Demographic, economic and technological developments, together with energy efficiency and climate policies influence the evolution of total domestic GHG emissions. To better understand the evolution of emissions, it is necessary to disentangle the determining factors contributing to emissions increase or decrease. Is the observed emission reduction due primarily to decarbonization of energy sources, increased imports, mild winters or low economic growth? To answer such a question in detail, it is necessary to use methods referred to in the literature as "decomposition analysis".

There are two main types of methods: index decomposition analyses (IDAs) and structural decomposition analyses (SDAs). IDAs are simpler and faster to implement because they require less data. They are typically used to disentangle the respective contributions of aggregated GDP, energy efficiency and population. Conversely, SDAs make it possible to include more factors in the analysis. In particular they allow highlighting of the role of consumption patterns and the evolution of the production system. They can address questions such as: Is consumption shifting towards services rather than industrial goods? Are the productive sectors more dependent on imports, and do they use less carbon-intensive intermediate consumption? Such factors can be key in explaining emission changes (Kwok et al., 2018). The SDA approach is therefore richer, but also more complex. Above all, SDAs require data which takes longer to produce: input-output tables of national accounts, adjusted for price changes. These tables provide an accurate picture of the economy, including the links between demand and production and crosssectoral trade at a detailed level (for example, 64 production sectors are distinguished by Eurostat). Data collection and statistical verification generally involve a time lag of at least four years for the production of these tables - and such production is often not done annually. The analysis of drivers for GHG emissions therefore results in a trade-off between speed of preparation and richness of analysis: IDAs are faster to prepare; SDAs provide a richer picture. More in-depth discussion on the differences between IDAs and SDAs are available in the literature (Hoekstra et al., 2003; Su and Ang, 2012; Wang et al., 2017).

A more detailed analysis may be particularly important in the case of major economic upheavals. Production and consumption structures can be altered, and thus affect emissions directly and indirectly. However, no SDA has been carried out on Europe since the 2008 crisis.

Recent literature on the decomposition of European GHG emissions is limited: there have been only three SDAs published since 2013, and none of them have studied European emissions beyond 2009. Duarte et al. (2013) analyzed the emissions of ten European countries between 1995 and 2005. They showed that the effect of technological change and efficiency improvements were not enough to compensate for economic growth. Brizga et al. (2014) studied emissions from the Baltic countries (Estonia, Latvia, Lithuania) between 1995 and 2009. They highlighted that the increase in emissions was mostly due to economic growth, partially offset by declining emission intensity in Latvia and Lithuania, and by shifts in consumption patterns and production structure in Estonia. Cansino et al. (2016) decomposed Spanish emissions between 1995 and 2009 and concluded that the promotion of renewable energy contributed to emission reduction.

By contrast, there has been a high number of IDA studies, due to the lower data requirements of this approach. Xu and Ang (2013) reviewed more than 80 studies. More recently, the IDA method has been used by Moutinho et al. (2015) to study the evolution 
of $\mathrm{CO}_{2}$ emissions in Europe. Cansino et al. (2016) studied Spanish emissions. Peters et al. (2017) used IDA to monitor alignment with the Paris Agreement for five regions, including the EU28. Finally, Le Quéré et al. (2019) analyzed the drivers of $\mathrm{CO}_{2}$ emissions in 18 developed economics over the period 2005-2015.

This small number of recent SDA studies is probably linked to the lack of recent data, and in particular of deflated input-output tables. Previous analyses were conducted using the deflated input-output tables of the World Input-Output Database (WIOD). However, the WIOD no longer provides these tables at constant prices for years past 2009. The latest release of the WIOD only provided tables at current prices, up to 2014. In contrast, in the United States, the US Bureau of labour statistics provides input-output tables for the United States up to 2013, which allowed Feng et al. (2015) to analyze national emissions between 1997 and 2013. This article generated controversial results on the role of natural gas in the US emissions decline, provoking a comment by Kotchen and Mansur (2016) on some aspects of its methodological approach.

Our study looks at the evolution of domestic emissions, in line with the European and international commitments of the EU Member States. It should be noted that this study does not consider imported emissions. While imported emissions are required to estimate carbon footprints, they require different methodological choices than those adopted here (Barrett et al., 2013).

A new, unique time series of price-adjusted input-output tables has been constructed to analyze the evolution of European emissions in detail, based on the latest available data. More precisely, this new database was built using tables for the period 2009-2014 for each of the 28 Member States. Price effects have been separated from volume effects, for each of the 56 economic sectors considered. Year 2014 was the last year for which input-output tables were available at the time of writing this article. While a more up-to-date data set would have been desirable, this is already a notable improvement over existing data. By comparison, the WIOD only provides deflated tables up to 2009. Exiobase, another well-recognized supplier of Input-Output tables, is about to release a new set of data (Exiobase 3 ) which will cover years up to 2011 only. The fully reproducible code used for the deflation procedure, as well as a detailed documentation of the method and data used for deflation have been made available at https://github.com/GICN/ Deflating_WIOD_Tables, so that this data set can be scrutinized and reused for further studies.

To disentangle the various drivers of emissions, the SDA methodology is tailored to the aim of this article and to our data set. The analysis is performed for each of the 28 Member States and for the European Union as a whole. Eight drivers are disentangled: carbon intensity of GDP; production structure; consumption patterns; wealth per capita; population; and household emissions related to heating, transport and other needs. Finally the analysis is extended to disentangle the influence of imports and technical changes in the production structure - drivers that are rarely considered in the literature.

Thanks to the unique data set built, this study represents a significant improvement to the available literature in terms of its use of the most recent data, geographical coverage and methodological originality. Our SDA is much more recent than the latest publications for European countries: it starts when the latest studies end (2009). It is therefore the first study to detail the evolution of European emissions since the 2008 economic crisis. In terms of coverage, our SDA is the first to include each of the 28 countries of the European 
Union, as well as the Union as a whole. Compared to the three recent European studies, it is also the only one to include the six GHGs of the Kyoto Protocol. Finally, from a methodological point of view, our adaptation of the SDA method makes it possible to highlight the role of factors that are not well studied, in particular the effects related to imports, consumption patterns and climate variations.

The purpose of this analysis is therefore to better understand the evolution of past emissions. A better understanding of the underlying emission drivers can help to better assess the results of policy efforts to date and better anticipate future developments. Finally, the identification of underlying drivers can feed into current thinking on the indicators to be put in place to monitor countries' emissions under the Paris Agreement.

In order to improve readability and communication, the results of this article have been translated into an interactive application, accessible at https://gicn.shinyapps.io/EU_emissions.

The remainder of the paper is organized as follows: section 2 presents the methodology and data, the analysis and results are in section 3 , and section 4 concludes.

\section{Materials and method}

\subsection{Data used}

The evolution of GHG emissions between 2009 and 2014 are broken down for 28 European Union countries, using the following data sets:

- WIOD Input-Output tables, published in 2016 (2016 release). The WIOD database provides input-output tables for 43 countries (28 European countries plus 15 major economies), distinguishing 56 economic sectors for the period 2000 to 2014. These tables are in national currencies. The rest of the world is aggregated as a single country, with the same structure and level of sectoral disaggregation as the other countries. The list of the 56 sectors can be found in the documentation which details our method and code, at github.com/GICN/Deflating_WIOD_Tables.

- The socio-economic accounts of the WIOD, published in February 2018. These accounts provide data on output, prices, capital stocks, and employment at a sectoral level.

- The exchange rate values provided by the WIOD, used to transform values in national currencies to values in 2010 USD. Our deflated tables will thus be in dollars, not euros; but this does not impact the results, as the SDA methodology considers the relative variation of each parameter.

- GHG emissions accounts provided by Eurostat (database env_ac_ainah_r2). These emission accounts provide the emission levels, in $\mathrm{CO}_{2}$ equivalent, for seven gases or family of gases: $\mathrm{CO}_{2}, \mathrm{~N}_{2} \mathrm{O}, \mathrm{CH}_{4}, \mathrm{HFC}, \mathrm{PFC}, \mathrm{SF}_{6}$ and $\mathrm{NF}_{3}$, using the global warming potentials of the IPCC $4^{\text {th }}$ assessment report. The emissions recorded are those of resident units, as defined in the national accounts. In particular, they do not include direct emissions from foreign tourists in the territory. Emissions from land use, land use change and forestry (LULUCF) are also not included in this data set. 


\subsection{Input-Output table deflation}

The WIOD tables are provided in current prices and therefore provide useful information on the economy each year. However, for time series analyses, volume variations must be disentangled from price effects. All tables must be converted from current prices to constant prices, i.e. into a common currency for a single year. This procedure is known as 'deflation'.

The previous version of WIOD (2013 release) provided deflated input-output tables, but the newest 2016 release is only available at current prices. However, in February 2018, WIOD published the socio-economic accounts (SEA) associated with the input-output tables. These SEA include price deflators for each sector and each year.

By using the new information provided by the socio-economic account, we undertook the deflation of WIOD tables. We applied the method used by Los et al. (2014) to convert WIOD tables, initially in current prices and national currencies, into tables in 2010 US dollars (USD). The exact procedure followed is detailed in the supplementary material "Deflating Input-Output Tables from WIOD". The corresponding R code can be freely downloaded at github.com/GICN/Deflating_WIOD_Tables, along with the documentation. The results of this important preliminary work are new deflated tables with output, value added and demand in constant prices for each sector, as well as for the intermediate consumption matrix. The code and the resulting tables are provided in full, ensuring the transparency of our method and encouraging the reuse of our data for other studies.

\subsection{Decomposition method}

EU emissions are broken down using the SDA approach. Using input-output analysis, industrial emissions can be linked to five drivers: population, consumption per capita, consumption structure, production structure and carbon intensity of production. The full methodology is explained in section A.2 in appendix, and leads to the following equation:

$$
G H G^{i n d}=\boldsymbol{c}^{T} \cdot \boldsymbol{L} \cdot \boldsymbol{s} \cdot y \cdot p
$$

The notation here follows the conventions of Miller and Blair (2009), where a bold and lowercase letter indicates a column vector, and a bold and capital letter indicates a square matrix. Here $G H G^{i n d}$ represents total industrial emissions; $\boldsymbol{c}$ is the vector of carbon intensity of production, equal to the GHG emissions divided by the output in each sector; $T$ is the transposition operator; $\boldsymbol{L}$ is the Leontief matrix representing the production structure; $\boldsymbol{s}$ is the structure of consumption; $y$ is the average per-capita expenditure and $p$ is population. Emissions are estimated using a single-region approach (SRIO), which is suited to the study of domestic emissions. In this framework, imports are treated as noncompetitive in the sense of Su and Ang (2013). However, this assumption is not crucial for our results, as this paper considers domestic emissions, not imported emissions.

To obtain total GHG emissions, one must add direct emissions from households, i.e., all GHG emissions from a source owned or controlled by a household -such as emissions from the use of petrol in their car or fuel oil to heat their house. Emissions from households, $G G^{\text {hous }}$, can be broken down into three categories provided by Eurostat: 
transport emissions, heating and cooling emissions, and other emissions.

$$
G G^{\text {hous }}=H H_{\text {transp }}+H H_{\text {heat }}+H H_{\text {others }}
$$

where the "Others" emissions are low in practice (see section A.3 for more information on this equation).

Finally, since the accuracy of the input-output data is not perfect, an error term $\epsilon$ should be added to ensure equality between the two sides of the equation. This error term is due to a slight difference, in the WIOD input-output tables that were deflated, between the sum of the added values on the one hand, and the sum of final expenditures plus exports minus imports on the other hand. The appearance of this difference is linked to the deflation method used. Rather than hiding this difference by arbitrarily allocating it to stock and inventory changes, it was made explicit to ensure that it remains negligible.

Combining equations 7 and 2 and adding the error term yields:

$$
G H G=\boldsymbol{c}^{T} \cdot \boldsymbol{L} \cdot \boldsymbol{s} \cdot y \cdot p+H H_{\text {transp }}+H H_{\text {heat }}+H H_{\text {others }}+\epsilon
$$

A total differentiation then gives:

$$
\begin{aligned}
\Delta G H G= & \Delta \boldsymbol{c}^{T} \cdot \boldsymbol{L} \cdot \boldsymbol{s} \cdot y \cdot p+\boldsymbol{c}^{T} \cdot \Delta \boldsymbol{L} \cdot \boldsymbol{s} \cdot y \cdot p+\boldsymbol{c}^{T} \cdot \boldsymbol{L} \cdot \Delta \boldsymbol{s} \cdot y \cdot p+ \\
& \boldsymbol{c}^{T} \cdot \boldsymbol{L} \cdot \boldsymbol{s} \cdot \Delta y \cdot p+\boldsymbol{c}^{T} \cdot \boldsymbol{L} \cdot \boldsymbol{s} \cdot y \cdot \Delta p+ \\
& \Delta H H_{\text {transp }}+\Delta H H_{\text {heat }}+\Delta H H_{\text {others }}+\Delta \epsilon
\end{aligned}
$$

Changes in GHG emissions are thus decomposed into a sum of nine terms, eight corresponding to the variation of one of the parameters identified in the decomposition, plus one error term. Each term and its meaning in terms of drivers is detailed in table 1.

Table 1: Definition of the factors studied.

More information can be found in section A.4 in appendix.

\begin{tabular}{ll}
\hline Term & Driver \\
\hline$\Delta \boldsymbol{c}^{T} \cdot \boldsymbol{L} \cdot \boldsymbol{s} \cdot y \cdot p$ & Carbon intensity of production \\
$\boldsymbol{c}^{T} \cdot \Delta \boldsymbol{L} \cdot \boldsymbol{s} \cdot y \cdot p$ & Production structure \\
$\boldsymbol{c}^{T} \cdot \boldsymbol{L} \cdot \Delta \boldsymbol{s} \cdot y \cdot p$ & Final consumption structure. \\
$\boldsymbol{c}^{T} \cdot \boldsymbol{L} \cdot \boldsymbol{s} \cdot \Delta y \cdot p$ & Level of wealth per capita \\
$\boldsymbol{c}^{T} \cdot \boldsymbol{L} \cdot \boldsymbol{s} \cdot y \cdot \Delta p$ & Population \\
$\Delta H H_{\text {transp }}$ & Household transport emissions \\
$\Delta H H_{\text {heat }}$ & Household heating and cooling emissions \\
$\Delta H H_{\text {others }}$ & Other direct household emissions \\
$\Delta \epsilon$ & An error term \\
\hline
\end{tabular}

In practice, differentiation is computed in this paper following the mean-value approach, as recommended by Dietzenbacher and Los (1998). An advantage of this ap- 
proach is to reveal the ranges of uncertainty which are inherent in such a differentiation. The reader is referred to appendix A.5 for more details.

\section{Results}

\subsection{Emissions trends for the European Union as a whole, 2009- 2014}

We apply the methodology presented in the previous section, in order to disentangle the relative contributions of the eight emission drivers for the period 2009-2014. The results are shown in figure 2 .

Over the whole period, the first factor of variation is by far the decrease in the carbon intensity of production, amounting to $-394 \mathrm{MtCO}_{2} \mathrm{e}$. These improvements in carbon intensity were only partly mitigated by the increase in per capita wealth, which amounted to $285 \mathrm{MtCO}_{2} \mathrm{e}$. These two factors are the largest ones, and also the most intuitive ones. But taken together, they only explain a reduction of $70 \mathrm{MtCO}_{2} \mathrm{e}$, against a total of -359 $\mathrm{MtCO}_{2} \mathrm{e}$ observed over the period. Some secondary factors thus played a major role in the emission decrease. These factors were, by order of importance, the transformation of the production structure $\left(-104 \mathrm{MtCO}_{2} \mathrm{e}\right)$; changes in the consumption structure ($\left.101 \mathrm{MtCO}_{2} \mathrm{e}\right)$; a decrease in direct emissions from households related to heating and cooling $\left(-83 \mathrm{MtCO}_{2} \mathrm{e}\right)$ and to transport $\left(-24 \mathrm{MtCO}_{2} \mathrm{e}\right)$. The only counteracting effect among these other factors was the growth in population, which pushed emissions up by $39 \mathrm{MtCO}_{2}$ e. Figure 2 also confirms that the error term $\Delta \epsilon$ is small compared to other values $\left(-1 \mathrm{MtCO}_{2} \mathrm{e}\right)$.

The decomposition method used in this paper allows us to estimate the uncertainty of the results obtained (see section 2.3 and appendix A.5). Our sensitivity analysis indicates that the relative order and sign of the factors are robust (see appendix A.6).

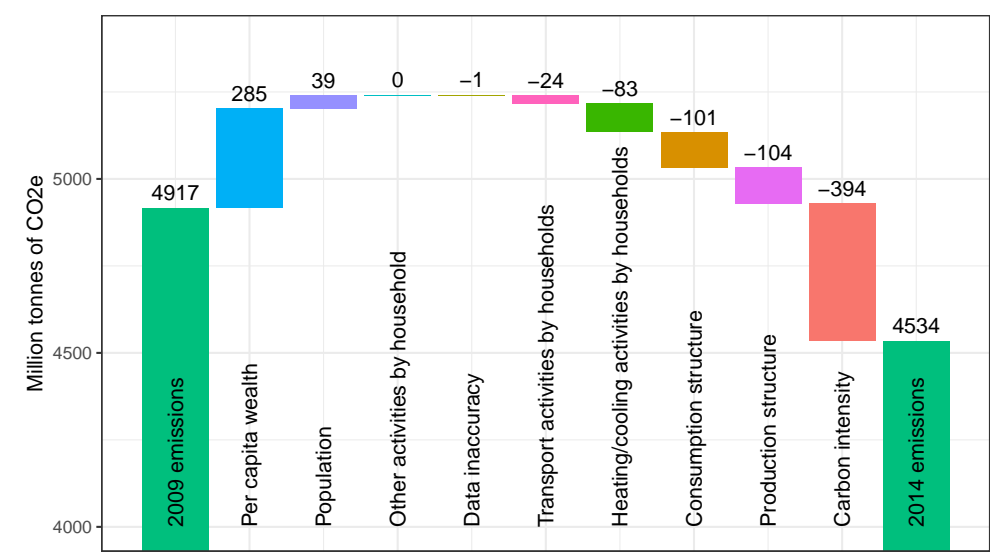

Figure 2: Drivers of EU GHG emission variations, 2009-2014. The factors are represented by decreasing order of contribution. This order may therefore vary for other geographical areas or other periods. Also note that the $y$-axis does not start at zero. 


\subsection{Annual European dynamics}

One can go further in the analysis by showing annual changes, in order to study more finely the dynamics at play. This work is shown in figure 8 .

Figure 8 indicates that the improvement in carbon intensity has been continuous, except between 2011 and 2012. Conversely, per capita wealth has been a stable upward factor, except between 2011 and 2012. Production structure played a major role in the rise from 2009 to 2010, then contributed to the fall in emissions until the end of the period. Consumption structure contributed to a decrease in emissions over each period, except for a slight increase in 2010-2011. Direct household emissions related to heating and cooling increased in 2009-2010, then declined sharply in 2010-2011 and 2013-2014. This swift variation can be linked to temperature anomalies: the years 2011 and 2014 were marked by milder winters, with a low number of heating degree days in the EU (figure $15 \mathrm{a}$ in appendix). Finally, transportation contributed to a slight decrease in emissions until 2012, and a very slight increase in 2013-2014.

Compared to IDA or sectoral analyses, the specificity of our SDA methodology is to show the impacts of consumption patterns and production structures. We will therefore focus our analysis on these two points, in sections 3.3 and 3.4, respectively, in order to better understand the meanings and implications of these effects. Finally, we will explore the diversity of national trajectories in section 3.5, with a country-by-country analysis of the largest emitters.

\subsection{Consumption structure}

The effect of consumption structure corresponds to a change in the distribution of final demand between sectors. To better understand these changes in final demand and their implications on emissions, the total "consumption structure" effect can be broken down into the contributions associated with each sector. The methodology is described in appendix A.8.

Our results indicate that the downward trend in emissions due to the consumption structure over the period 2009-2014 is strongly driven by a relative fall in final demand in the electricity and gas sector (code D35 in the NACE R2 Eurostat classification), with also a notable fall in agriculture (A01), agri-food (C10-C12) and construction (F). These emission decreases are limited by increases in the final demand share allocated to other sectors, in particular the metals (C24) and coking and refining (C19) sectors. This is shown in figure 9.

This significant fall in demand in the electricity and gas sector (D35) is more specifically linked to two factors: a fall in household expenditures and a decline in exports both in volume and in share of the total final consumption (this is shown in figure 11 in appendix). The decrease in the household budget can be explained by a decrease of about $10 \%$ in the number of heating degree days in the European Union over this period: from 80,212 in 2009 to 72,128 in 2014 (Eurostat, database nrg_chdd_a). This might be attributed to climate variability with a possible influence of a long-term climate change, but the strong decline over this particular period is quite sensitive to the period chosen, with a fairly mild 2013/2014 winter. Extending the period up to 2016, for example, would see a lower decline to 78,500 heating degree days. Besides, a limitation of our data set is that it does not separate electricity and gas, which does not allow to make a 
specific analysis for each of these energy carriers.

For the agri-food sector, there is a decrease in the proportion of expenditures allocated to agricultural products over the period 2009-2014, driven by a decline in the share of the budget allocated by households, and offset by a slight increase in exports in total final demand. Figure 9 highlights that this decrease comes mainly from the year 20092010. The most likely explanation is that this is a readjustment following the food price crisis over the period 2006-2008, when prices reached a world peak in 2008 (FAO, 2011). Finally, for the construction sector, there is a decline in investment relative to total final demand.

Geographically, the downward structural effect is mainly due to Germany, the United Kingdom and Italy, which account for $-48 \mathrm{MtCO}_{2} \mathrm{e},-25 \mathrm{MtCO}_{2} \mathrm{e}$ and $-16 \mathrm{MtCO}_{2} \mathrm{e}$, respectively. The structural effect was slightly positive in eight countries, and quite strong in Spain with $+20 \mathrm{MtCO}_{2} \mathrm{e}$ (see figure 12 in appendix). The reduction in emissions linked to a reduction in consumption in the electricity and gas sector is shared among most European countries. The effect is most pronounced in Germany $\left(-37 \mathrm{MtCO}_{2} \mathrm{e}\right)$, although two countries have a positive contribution: Spain $\left(+2.8 \mathrm{MtCO}_{2} \mathrm{e}\right)$ and Ireland $\left(+1.8 \mathrm{MtCO}_{2} \mathrm{e}\right)$, as shown in figure 13 in appendix.

\subsection{Production structure}

The structural effect of production contributed markedly to the fall in emissions over the period as a whole. To understand this better, we break it down into two effects: an effect purely due to technical change in the production function, and an effect related to changes in imports. This methodology, which has not previously been applied in SDA analysis to our knowledge, is indicated in appendix A.9.

The result of this breakdown between technical changes and imports is shown in figure 3a. Over the whole period, the increase in imports played a major role, reducing emissions by $-76.5 \mathrm{Mt} \mathrm{CO}_{2}$ e. The role of technological change is three times less, with a contribution of $-27.8 \mathrm{Mt} \mathrm{CO}_{2} \mathrm{e}$. In addition, the sign of the technological change is not entirely determined, since zero is included in the range of uncertainties of our mean-value decomposition method (refer to section 2.3 and appendix A.5 for an explanation on how uncertainties are computed).

The analysis of annual variations, shown in figure 3b, highlights that both technical change and imports influence emission variations, but the sign of their contributions varies along time. An increase in imports strongly reduced emissions between 2009 and 2011, while a decrease in imports increased emissions between 2012 and 2013.

Technological changes first pushed emissions up between 2009 and 2011 and then contributed to emission reductions up to 2014.

\subsection{Country-by-country analysis}

A comparison between countries shows that the emission drivers were very different from one country to another. The results for all the $28 \mathrm{EU}$ countries are accessible on an interactive app: gicn.shinyapps.io/EU_emissions. Here, we present the results for the top six EU emitters: Germany, the United Kingdom, France, Italy, Poland and Spain (figure 4). These six countries accounted for $68 \%$ of the EU's total GHG emissions in 2014. 


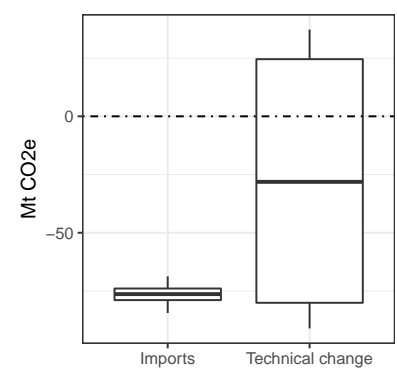

(a) Uncertainty range of technical change and imports contributions

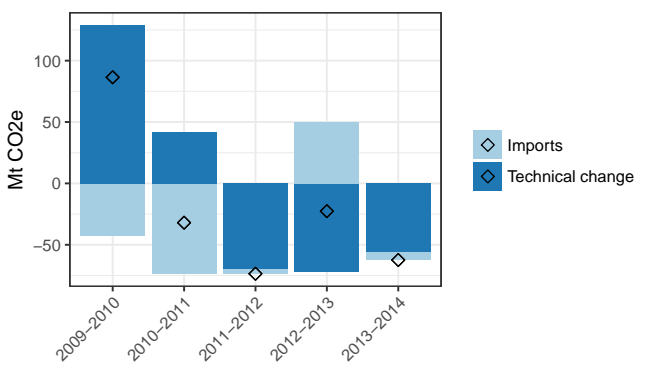

(b) Annual contributions of technical change and imports

Figure 3: Respective contributions of technical change and imports to EU emissions variations, 20092014.

Germany is the only one of the six countries where carbon intensity has not decreased. This is mainly due to developments in the electricity sector between 2011 and 2013: the closure of eight nuclear reactors following the Fukushima accident, the fall in coal prices with the shale gas revolution in the US and the low carbon prices on the European market, which all contributed to favouring coal over gas and nuclear energy. Per capita growth was particularly high over the period, but it was offset by very strong structural effects on the production system and the consumption basket.

The United Kingdom is characterized by strong population growth, mainly driven by immigration (Randall, 2017), and by an increasingly emissions-intensive production structure. However, net emissions have decreased, mainly due to great progress in carbon intensity.

France has experienced strong reductions in heating-related emissions, in part driven by large variations in heating degree days (see figure 15b in appendix). Combined with relatively low GDP per capita growth, improvements in energy intensity have reduced total emissions.

In Italy, per capita growth was negative over the period. Combined with improved energy efficiency and changing consumption patterns, the country achieved the largest emission reductions in Europe over the period in absolute terms, and the largest in relative terms among the six countries studied.

In Poland, GDP per capita growth has been particularly strong, but the significant improvement in energy intensity has stabilised emissions. The absence of population growth can be linked to a low birth rate and continued emigration (Devictor, 2012).

Finally, in Spain, the contribution from growth was close to zero, and even slightly negative. The structural effects of production and consumption played a role, but the reduction in carbon intensity was the second largest, resulting in an overall reduction of the total emissions for that country.

For the rest of the countries, the dynamics of change vary greatly from one country to another. We have not been able to identify groups of countries with common dynamics. At a more aggregated level, the usual comparison between Eastern and Western EU countries shows similar dynamics (see figure 17). In both Western and Eastern countries, GDP growth pushed emissions up, while improvements in carbon intensity and 

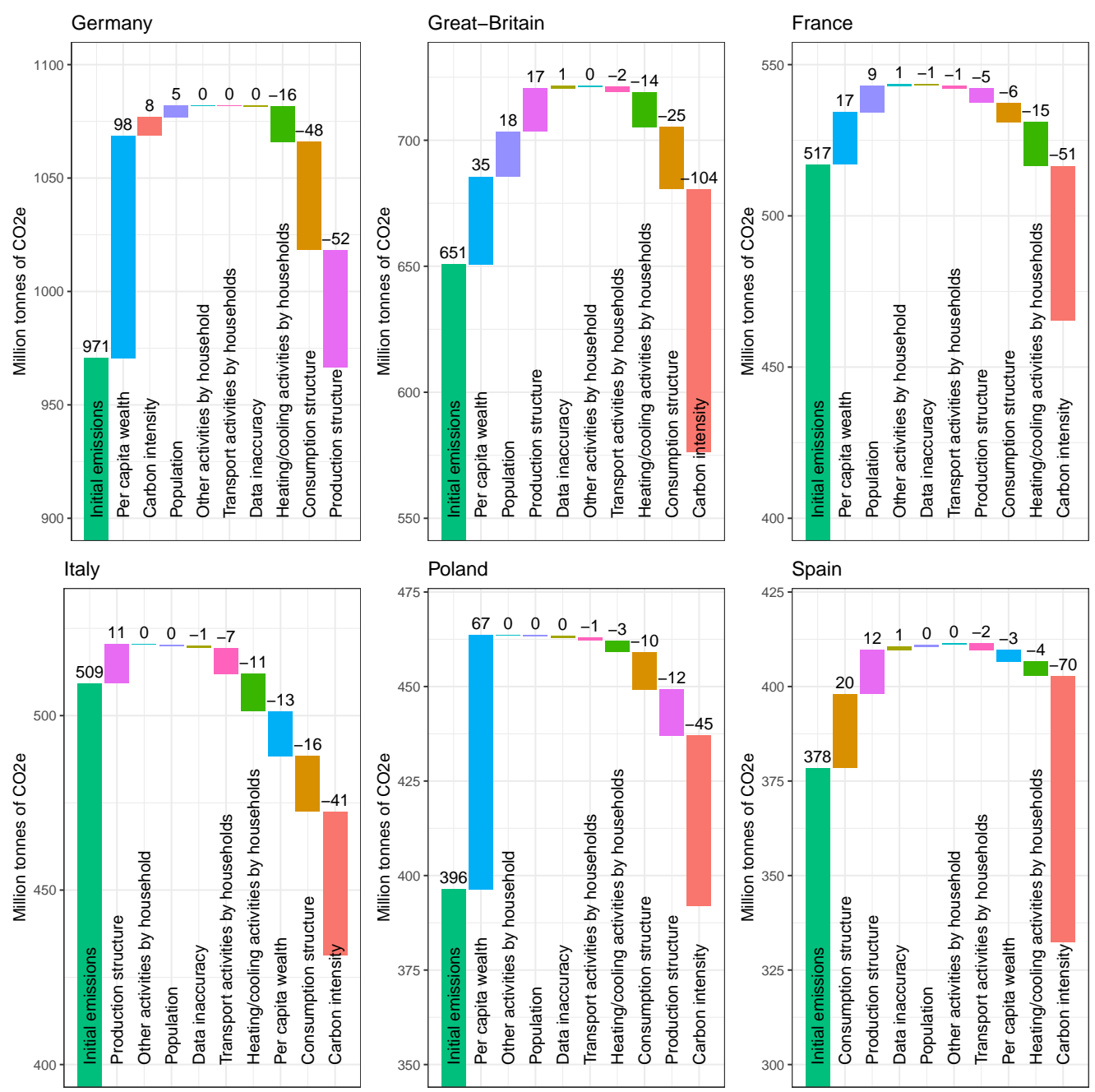

Figure 4: Drivers of emissions for the six largest EU emitters, 2009-2014. Note that the y-axis does not start at zero and varies for each country, and that the order of drivers depends on the country, as they are ordered by decreasing order.

changes in production and consumption patterns pushed emissions down. However, in Western Europe, the improvement in carbon intensity was more pronounced, and heating emissions also fell more sharply.

\section{Discussion and conclusion}

Over the period 2009-2014, the evolution of GHG emissions is mainly explained by an improvement in carbon intensity $\left(-394 \mathrm{MtCO}_{2} \mathrm{e}\right)$, largely offset by the post-crisis economic recovery $\left(+285 \mathrm{MtCO}_{2}\right)$. However, our SDA also shows that other factors played 
an important role in the decline of emissions: the evolution of the production structure $\left(-104 \mathrm{MtCO}_{2} \mathrm{e}\right)$, driven by increased imports and technical changes; the evolution of consumption and investment patterns $\left(-101 \mathrm{MtCO}_{2} \mathrm{e}\right)$ and the decrease in direct emissions linked to household heating and cooling $\left(-83 \mathrm{MtCO}_{2} \mathrm{e}\right)$ and household transport $(-24$ $\left.\mathrm{MtCO}_{2} \mathrm{e}\right)$. These effects were slightly offset by population growth $\left(+39 \mathrm{MtCO}_{2} \mathrm{e}\right)$.

\subsection{Comparison with other results}

Our approach provides a global overview of the main drivers of EU emissions trends. This approach is complementary to more detailed sector studies, based on dedicated modelling or econometric analyses, and to IDA studies.

The decrease in carbon intensity in Europe has been studied by Peters et al. (2017), using an IDA. In their analysis, they break down the evolution of emissions into three factors: GDP, energy intensity (energy/GDP) and carbon intensity $\left(\mathrm{CO}_{2} /\right.$ energy). They show that carbon intensity has continuously decreased over the period 2009-2014 at the EU level, dragging emissions down. Our results also highlight a decrease of carbon intensity every year, except for the year 2011-2012 where we find a small positive effect. Our SDA indicates that the production structure played a significant role in reducing emissions that year - a driver that their IDA approach could not identify, which might explain the difference.

In another IDA study, Le Quéré et al. (2019) show that the decrease in EU emissions was strongly driven by a decrease in energy use. However, they do not detail the respective shares of GDP, energy intensity and carbon intensity at the EU or country level. The fact that they consider only $\mathrm{CO}_{2}$ while ignoring other GHGs further complicates the comparison. If we combine our three drivers of per capita wealth, population and carbon intensity to match their 'energy use' driver, we also find a significant source of emission decrease $\left(-70 \mathrm{GtCO}_{2}\right)$. However, this effect is smaller than those due to production structure and consumption structure. Our SDA approach has thus revealed new, significant drivers that are not accessible to IDAs.

For the transport sector, sections 3.1 and 3.2 showed that transport activities by households contributed to a slight decrease in emissions over the period $\left(-24 \mathrm{GtCO}_{2} \mathrm{e}\right)$, with a decrease until 2012, and a very slight increase in 2013-2014. This aggregate evolution of transport emissions can be broken down more precisely, according to fuel types, emission intensity of different vehicles, level of activity, and several other factors. Although such a detailed analysis is beyond the scope of our study, the link can be made with sector-specific studies. In particular, Andrés and Padilla (2018) made a detailed analysis of EU transport activities from 1990 to 2014 using the STIRPAT model. They find that population and transport energy intensity have been the two main drivers of emissions trends in the EU transport sector, with a smaller but noticeable contribution from economic activity and transport volumes.

As for the impact of climate on energy consumption, Bréon et al. (2017) also inferred an impact of mild winters on emission reductions in Germany, the United Kingdom, France, Italy and Poland over the period 2009-2014 using a different methodology. 


\subsection{Future developments}

This analysis of past years may help to anticipate future developments. The global economic recovery seems to have continued and may have remained the largest driver pushing emissions up, unless a new economic crisis occurs. Demography can be expected to keep playing a small upward role in the next decade. The European population should grow moderately until 2045, by $+4.4 \%$ compared to 2014 , before gradually declining (Eurostat, proj_15npms, baseline scenario). In comparison, the EU population increase was $1 \%$ over the period 2009-2014.

On the contrary, carbon intensity and transport might push emissions down. The improvement of carbon intensity could continue, as the European electricity mix is still highly carbon intensive. In 2017, gas and coal-fired power plants produced $40 \%$ of the electricity in Europe (Jones et al., 2018), while the costs of solar panels and wind generation continued to fall (IRENA, 2017). However, the "integration costs" associated with these variable renewable energies could limit their expansion (Hirth, 2014). Transportation is another key sector for reducing emissions. With the rapid decarbonization of the electricity sector, transportation has become the main emitting sector in 2014 (European Environment Agency, 2016). A shift to electric vehicles, coupled to a decarbonization of electricity production, could be an important lever to reduce European transportation emissions (Moro and Lonza, 2017).

Finally, the future net effects of heating and cooling, production structure and consumption patterns are more ambiguous. Heating emissions could recover in the short term, as 2014 was a particularly mild year. In the longer term, milder winters associated with climate change could reduce heating emissions. However, this positive feedback may be weakened or even offset by an increase in air conditioning (De Cian et al., 2016). Concerning the structure of consumption, the key sectors were shown to be electricity and gas production, as well as agriculture and the agri-food industry. It is possible to reduce the emission share of the electricity and gas sector by encouraging thermal insulation measures and the energy efficiency of domestic appliances and heating systems. For the agri-food sector, a shift towards a more vegetarian diet, for example, could reduce emissions from agriculture (Stehfest et al., 2009). On the production side, the analysis of the production structure has shown the dominant role of increased imports. In the short term, the strengthening of climate policy measures, such as the expected increase in the carbon price on the European Emission Trading Scheme following the entry into force of the Market Stability Reserve (Mark Lewis, 2018), could reinforce these carbon leaks, even though econometric studies seem to show a rather limited effect (Branger et al., 2015).

\subsection{Conclusion}

In conclusion, this work provides new quantitative information on the drivers behind GHG emission reductions in Europe, highlighting their multidimensional nature. Although carbon intensity and economic recovery were the main drivers, the contributions of consumption structure, production structure and temperature anomalies also played a major role.

This article also makes a significant contribution by providing a methodology and indicators that could be used to track progress towards the Paris Agreement goals (Peters 
et al., 2017; Green, 2017; Spencer et al., 2017; Iyer et al., 2017; Mathy et al., 2018) or to define when a country's emissions have "peaked", in line with Article 4.1 of the Paris Agreement. Our results indicate that import rates, household emissions linked to heating and cooling and household emissions in transport are important drivers of total emissions. Thus, they should appear in any set of tracking indicators. In addition, the importance of climate-related variations suggests it could be appropriate to consider climate-adjusted emissions, at least for short-term targets. Our results could also be used in future evaluations of climate policies implemented in European countries. Indeed, the evaluation of climate policies should not be based on observed emissions alone. This study has shown that many drivers can be at play, some of them not directly linked to climate policies, like GDP growth, climate variability, or population changes. Conversely, the evolution of emissions driven by carbon intensity, which can only be disentangled by SDAs such as this one, may be more closely related to energy policies.

Finally, the importance of production and consumption patterns in our results emphasises the need for more analyses on the subject and better monitoring of their trends. A first step would be to improve the availability of data on national accounts. Currently, only four European countries provide product-by-product input-output tables on an annual basis: Austria, Germany, France and Sweden (see Eurostat database naio_10_cp1700); and the generation of these tables currently takes four years. A better harmonization of data generation across countries, and a faster publication process for example through a two-step publication of preliminary and then consolidated data could greatly improve the necessary task of tracking progress towards the Paris Agreement goals. Besides, such improvements would also benefit the analysis of imported emissions and carbon footprints, which also relies on input-output tables. These data sets are thus crucial to measure progress towards "carbon neutrality", which, according to IPCC (2018), has to be achieved globally by 2050 for limiting temperature to $1.5^{\circ} \mathrm{C}$.

\section{Disclosure statement}

This work has received funding from the French Convention on financial support for climate services.

\section{Data availability}

The data that support the findings of this study are available at https://github.com/ GICN/Deflating_WIOD_Tables. These data were derived from the World Input-Output Database, Release 2016, available at http://www.wiod.org. 


\section{Bibliography}

Andrés, L., Padilla, E., 2018. Driving factors of GHG emissions in the EU transport activity. Transport Policy 61, 60-74. doi:10.1016/j.tranpol.2017.10.008.

Barrett, J., Peters, G., Wiedmann, T., Scott, K., Lenzen, M., Roelich, K., Le Quéré, C., 2013. Consumption-based GHG emission accounting: a UK case study. Climate Policy 13, 451-470. doi:10.1080/14693062.2013.788858.

Branger, F., Lecuyer, O., Quirion, P., 2015. The European Union Emissions Trading Scheme: should we throw the flagship out with the bathwater? Wiley Interdisciplinary Reviews: Climate Change 6, 9-16. doi:10.1002/wcc.326.

Bréon, F.M., Boucher, O., Brender, P., 2017. Inter-annual variability in fossil-fuel CO2 emissions due to temperature anomalies. Environmental Research Letters 12, 074009. doi:10.1088/1748-9326/aa693d.

Brizga, J., Feng, K., Hubacek, K., 2014. Drivers of greenhouse gas emissions in the Baltic States: A structural decomposition analysis. Ecological Economics 98, 22-28. doi:10.1016/j.ecolecon.2013. 12.001.

Cansino, J.M., Román, R., Ordóñez, M., 2016. Main drivers of changes in CO2 emissions in the Spanish economy: A structural decomposition analysis. Energy Policy 89, 150-159. doi:10.1016/j.enpol. 2015.11.020

De Cian, E., Sue Wing, I., Wing, I.S., 2016. Global Energy Demand in a Warming Climate. Environmental and Resource Economics , 1-46doi:10.1017/CB09781107415324.004, arXiv:arXiv:1011.1669v3.

Devictor, X., 2012. Poland: Aging and the Economy. Technical Report. The World Bank.

Dietzenbacher, E., Los, B., 1998. Structural Decomposition Techniques: Sense and Sensitivity. Economic Systems Research 10, 307-324. doi:10.1080/09535319800000023.

Duarte, R., Mainar, A., Sánchez-Chóliz, J., 2013. The role of consumption patterns, demand and technological factors on the recent evolution of $\mathrm{CO} 2$ emissions in a group of advanced economies. Ecological Economics 96,1-13. doi:10.1016/j.ecolecon.2013.09.007.

European Environment Agency, 2016. Annual European Union greenhouse gas inventory 1990-2014 and inventory report 2016. Technical Report 15. Submission to the UNFCCC Secretariat.

Eurostat, 2008. Statistical classification of economic activities in the European Community. doi:KS-RA-07-015-EN-N

FAO, 2011. Lessons from the world food crisis of 2006-08. The State of Food Insecurity in the World $20112008,21-31$.

Feng, K., Davis, S.J., Sun, L., Hubacek, K., 2015. Drivers of the US CO2 emissions 1997-2013. Nature Communications 6, 7714. doi:10.1038/ncomms8714, arXiv: arXiv:1507.02142v2.

Green, C., 2017. Mitigation technology: Half full or nearly empty? Nature Climate Change 7, 98-99. doi:10.1038/nclimate3205.

Hirth, L., 2014. The Optimal Share of Variable Renewables: How the Variability of Wind and Solar Power affects their Welfare-optimal Deployment. The Energy Journal 36. doi:10.5547/01956574.36.1.5.

Hoekstra, R., Van Der Bergh, J.J.C.J.M., Bergh, J.J.C.J.M.V.D., 2003. Comparing structural and index decomposition analysis. Energy Economics 25, 39-64. doi:10.1016/S0140-9883(02)00059-2.

IPCC, 2018. IPCC special report on the impacts of global warming of $1.5{ }^{\circ} \mathrm{C}$ above pre-industrial levels and related global greenhouse gas emission pathways, in the context of strengthening the global response to the threat of climate change, sustainable development, a.

IRENA, 2017. Renewable Energy Auctions: Analysing 2016. Technical Report. International Renewable Energy Agency. Abu Dhabi.

Iyer, G., Ledna, C., Clarke, L., Edmonds, J., McJeon, H., Kyle, P., Williams, J.H., 2017. Measuring progress from nationally determined contributions to mid-century strategies. Nature Climate Change 7, 871-874. doi:10.1038/s41558-017-0005-9.

Jones, D., Sakhel, A., Buck, M., Graichen, P., 2018. The European Power Sector in 2017. Agora Energiewende and Sandbag .

Kotchen, M.J., Mansur, E.T., 2016. Reassessing the contribution of natural gas to US CO2 emission reductions since 2007. Nature Communications 7, 10648. doi:10.1038/ncomms 10648.

Kwok, T.F., Xu, Y., Liu, X., Leung, Y., 2018. The impacts of economic structure on China's carbon dioxide emissions: an analysis with reference to other East Asian economies. Climate Policy 18, 1235-1245. doi:10.1080/14693062.2017.1418282.

Le Quéré, C., Korsbakken, J.I., Wilson, C., Tosun, J., Andrew, R., Andres, R.J., Canadell, J.G., Jordan, A., Peters, G.P., van Vuuren, D.P., 2019. Drivers of declining CO2 emissions in 18 developed economies. Nature Climate Change 9, 213-217. doi:10.1038/s41558-019-0419-7.

Los, B., Gouma, R., Timmer, M., Ijtsma, P., 2014. Note on the Construction of WIOTs in Previous 
Year's Prices. Technical Report December. WIOD.

Mark Lewis, 2018. Carbon Clampdown: Closing the Gap to a Paris-compliant EU-ETS. Technical Report. Carbon Tracker.

Mathy, S., Menanteau, P., Criqui, P., 2018. After the Paris Agreement: Measuring the Global Decarbonization Wedges From National Energy Scenarios. Ecological Economics 150, 273-289. doi:10.1016/j. ecolecon.2018.04.012.

Miller, R.E., Blair, P.D., 2009. Input-Output Analysis, Foundations and Extensions. Cambridge University Press.

Moro, A., Lonza, L., 2017. Electricity carbon intensity in European Member States: Impacts on GHG emissions of electric vehicles. Transportation Research Part D: Transport and Environment doi:10. 1016/J. TRD. 2017.07.012.

Moutinho, V., Moreira, A.C., Silva, P.M., 2015. The driving forces of change in energy-related CO2 emissions in Eastern, Western, Northern and Southern Europe: The LMDI approach to decomposition analysis. Renewable and Sustainable Energy Reviews 50, 1485-1499. doi:10.1016/j.rser.2015.05. 072.

Nagashima, F., 2018. The sign reversal problem in structural decomposition analysis. Energy Economics 72, 307-312. doi:10.1016/J.ENEC0.2018.04.027.

Peters, G.P., Andrew, R.M., Canadell, J.G., Fuss, S., Jackson, R.B., Korsbakken, J., Le Quéré, C., Nakicenovic, N., 2017. Key indicators to track current progress and future ambition of the Paris Agreement. Nature Climate Change 7, 118-122. doi:10.1038/nclimate3202.

Randall, M., 2017. Overview of the UK population: July 2017. Technical Report. Office for national Statistics.

Spencer, T., Pierfederici, R., Sartor, O., Berghmans, N., Samadi, S., Fischedick, M., Knoop, K., Pye, S., Criqui, P., Mathy, S., Capros, P., Fragkos, P., Bukowski, M., Śniegocki, A., Rosa Virdis, M., Gaeta, M., Pollier, K., Cassisa, C., 2017. Tracking sectoral progress in the deep decarbonisation of energy systems in Europe. Energy Policy 110, 509-517. doi:10.1016/j.enpol.2017.08.053.

Stehfest, E., Bouwman, L., Van Vuuren, D.P., den Elzen, M.G.J., Eickhout, B., Kabat, P., 2009. Climate benefits of changing diet. Climatic Change 95, 83-102. doi:10.1007/s10584-008-9534-6.

$\mathrm{Su}$, B., Ang, B., 2013. Input-output analysis of CO2 emissions embodied in trade: Competitive versus non-competitive imports. Energy Policy 56, 83-87. doi:10.1016/J.ENPOL.2013.01.041.

Su, B., Ang, B.W.B., 2012. Structural decomposition analysis applied to energy and emissions: Some methodological developments. Energy Economics 34, 177-188. doi:10.1016/j.eneco.2011.10.009.

Wang, H., Ang, B.W., Su, B., 2017. Assessing drivers of economy-wide energy use and emissions: IDA versus SDA. Energy Policy 107, 585-599. doi:10.1016/j. enpol.2017.05.034.

$\mathrm{Xu}$, X.Y., Ang, B.W., 2013. Index decomposition analysis applied to CO2 emission studies. Ecological Economics 93, 313-329. doi:10.1016/j.ecolecon.2013.06.007. 


\section{Appendix A Appendix}

\section{A.1 Additional emissions drivers}

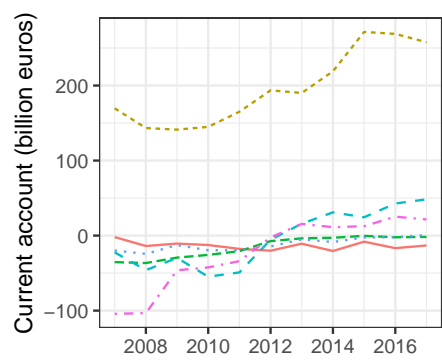

(a) Current accounts (billions euros)
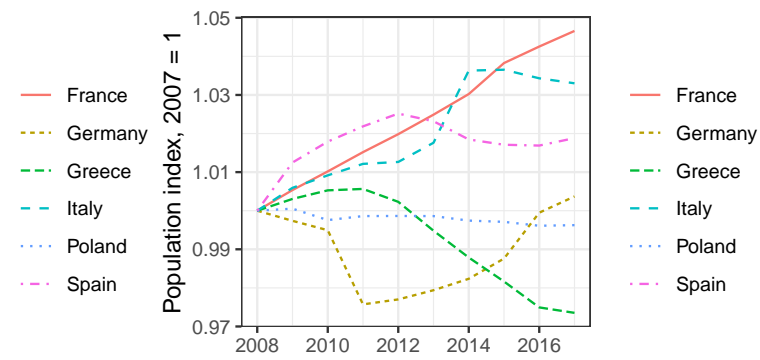

(b) Population, relative to 2007, of six European countries

Figure 5: Emissions drivers for six major EU28 economies

\section{A.2 Decomposing industrial emissions}

Input-output analysis is based on the balance between resources and uses in an economy. Vectorially, one can write:

$$
q=i c+f d
$$

The notation here follows here the conventions of Miller and Blair (2009), where a bold and lowercase letter indicates a column vector, and a bold and capital letter indicates a square matrix. $\boldsymbol{q}$ represents the production vector, $\boldsymbol{i c}$ the intermediate consumption vector, and $\boldsymbol{f} \boldsymbol{d}$ is the vector of total final demand, which aggregates household final consumption, government expenditure and investment.

Let us call $\boldsymbol{A}$ the matrix of technical coefficients, such that $\boldsymbol{i c}=\boldsymbol{A} \cdot \boldsymbol{q}$. Rearranging the previous expression and inverting a matrix gives the following equality:

$$
q=(I-A)^{-1} \cdot f d
$$

This equality is the fundamental equation of input-output analysis, which links demand and production. $\boldsymbol{I}$ is the identity matrix. $\boldsymbol{L}=(\boldsymbol{I}-\boldsymbol{A})^{-1}$ is called the Leontief matrix. It captures the inter-industry relationships within an economy, showing how the output of one sector can be used in other sectors. More precisely, each term $(i, j)$ of the Leontief matrix indicates the output needed in sector $i$ to satisfy a unit of final demand addressed to sector $j$.

To move from production to emissions, each member of the equation can then be multiplied by the carbon intensity vector $\boldsymbol{c}$, where $\boldsymbol{c}$ is defined as the amount of GHG emissions in sector $i, G H G_{i}^{i n d}$, per unit of production $P_{i}$ in this sector: $\forall i, \quad c_{i}=$ $G H G_{i}^{i n d} / P_{i}$, as commonly done in environmental input-output analysis. In vector form, total industrial emissions $G H G^{i n d}$ can then be linked to final demand using the formula: 


$$
G H G^{i n d}=\boldsymbol{c}^{T} \cdot \boldsymbol{L} \cdot \boldsymbol{f d}
$$

where ${ }^{T}$ indicates the transposition operator.

Final demand can be further decomposed to highlight the role of population $p$, final per capita expenditure $y=\frac{\sum_{i} f d_{i}}{p}$, and final demand structure $\boldsymbol{s}$, a vector that indicates the distribution key of final expenditure across different sectors, such that $s_{i}=\frac{f d_{i}}{\sum_{i} f d_{i}}$. Using a Kaya-like decomposition in a matrix way, one can write

$$
f d=s \cdot y \cdot p
$$

so that total industrial emissions are equal to:

$$
G H G^{i n d}=\boldsymbol{c}^{T} \cdot \boldsymbol{L} \cdot \boldsymbol{s} \cdot y \cdot p
$$

\section{A.3 Decomposing household emissions}

In this equation 2, "Others" refers to emissions from the purchase and combustion of fossil fuels by households that are not used for transport or heating: for example, gasoline in lawnmowers or brush-cutters. These emissions are very low in practice: about $2 \%$ of household GHG emissions in the European Union (see Eurostat database env_ac_ainah_r2). Note that household emissions $G G^{\text {hous }}$ only account for direct emissions in the classification of Eurostat. For example, in the case of domestic electric heating powered by coal-fired electricity, our decomposition would attribute the emissions to the electricity sector. These household emissions for transport and for heating and cooling could be further broken down into more drivers, but this would require the use of detailed sector-specific models for each sector. Such studies are beyond the scope of this paper. However, we make the link with existing sector studies in section 4.1.

\section{A.4 Drivers details}

It should be noted that the exact interpretation of the first two factors, the carbon intensity of production and the structure of production, depends on the level of disaggregation of the input-output tables used for the analysis.

In our 56-sector tables, "mining and quarrying" is a single sector, which includes coal, lignite, gas and oil extraction. Thus, a switch from coal to gas would result in reduced emissions, but without any change in the Leontief matrix. In this decomposition, the substitution effect would then be fully captured by the "carbon intensity of production" factor. Nevertheless, the use of more detailed input-output tables, with separate sectors for each energy source, would lead to attributing this emission reduction to a change in the production structure, as the Leontief matrix $\boldsymbol{L}$ would change.

Similarly, a limitation of our data set is that it does not separate electricity and gas, which does not allow a specific analysis to be made for each of these two energy carriers.

\section{A.5 Differentiation method}

There are several ways to implement the differentiation in equation 4. This is known as the problem of non-uniqueness in SDA solutions (Duarte et al., 2013). For each term 


\begin{tabular}{|c|c|}
\hline Term & Driver \\
\hline$\Delta \boldsymbol{c}^{T} \cdot \boldsymbol{L} \cdot \boldsymbol{s} \cdot y \cdot p$ & $\begin{array}{l}\text { Carbon intensity of production. A decrease indicates that the } \\
\text { production of one or more goods generates fewer direct emissions. }\end{array}$ \\
\hline $\boldsymbol{c}^{T} \cdot \Delta \boldsymbol{L} \cdot \boldsymbol{s} \cdot y \cdot p$ & $\begin{array}{l}\text { Production structure. A change indicates that the same good is } \\
\text { produced with a different combination of intermediate consump- } \\
\text { tions. This may result from a change in the production function of } \\
\text { this good (e.g., the replacement of steel parts by plastic polymers } \\
\text { in the automotive industry), or from intra-sectoral changes (e.g., } \\
\text { the substitution of gas-fired power plants by wind turbines will re- } \\
\text { duce gas consumption in the electricity sector). In the following, } \\
\text { we will group these two aspects under the heading of technical } \\
\text { changes. But this production structure also includes another phe- } \\
\text { nomenon: the change in import rates. An increase in imports will } \\
\text { reduce inputs in the intermediate consumption matrix } \boldsymbol{i c} \text {, and thus } \\
\text { modify the } \Delta \boldsymbol{L} \text { matrix. }\end{array}$ \\
\hline $\boldsymbol{c}^{T} \cdot \boldsymbol{L} \cdot \Delta \boldsymbol{s} \cdot y \cdot p$ & $\begin{array}{l}\text { Final consumption structure. This term may represent the fact } \\
\text { that consumption (as a share of total expenditure) is more ori- } \\
\text { ented towards low emitting sectors. The phenomenon of tertiari- } \\
\text { sation of the economy, for example, falls into this category. }\end{array}$ \\
\hline $\boldsymbol{c}^{T} \cdot \boldsymbol{L} \cdot \boldsymbol{s} \cdot \Delta y \cdot p$ & Level of wealth per capita \\
\hline $\boldsymbol{c}^{T} \cdot \boldsymbol{L} \cdot \boldsymbol{s} \cdot y \cdot \Delta p$ & Population \\
\hline$\Delta H H_{\text {transp }}$ & $\begin{array}{l}\text { Household transport emissions. Direct emissions from households } \\
\text { related to transport }\end{array}$ \\
\hline$\Delta H H_{\text {heat }}$ & $\begin{array}{l}\text { Household heating emissions. Direct emissions from households } \\
\text { related to heating and cooling }\end{array}$ \\
\hline$\Delta H H_{\text {others }}$ & $\begin{array}{l}\text { Other household emissions. Direct emissions from households, } \\
\text { other than transport, heating and cooling. They include, from } \\
\text { example, the fuel for gardening machines like lawnmower or chain } \\
\text { saw. }\end{array}$ \\
\hline$\Delta \epsilon$ & $\begin{array}{l}\text { An error term, due to the imperfect balance between output and } \\
\text { expenditures at the national level of deflated WIOD tables. }\end{array}$ \\
\hline
\end{tabular}

shown in table 1 , the value will depend on whether each variation is weighted by taking the other coefficients at their starting value or ending values. If $n$ is the number of terms that to analyze (in our case, $n=5$, as the SDA decomposition does not apply to household direct emissions), there is exactly $n$ ! possible forms of decomposition, corresponding to the $n$ ! possible permutations for the $n$ terms. Each form of decomposition (i.e. each permutation) might lead to different values for the drivers. These differences are small 
in practice, but they might change the sign of slightly positive or negative drivers, or the order between two drivers with close values.

This problem is well identified in the literature, and several approaches have been employed to address it. Three main approaches have been identified by Dietzenbacher and Los (1998). The first approach is the use of two polar cases, used by Miller and Blair (2009). This approach uses the average of two decompositions, which are chosen symmetrically: if the arrival value is used for one parameter in the first decomposition, then the starting value is chosen in the other decomposition - and conversely. The second approach is the use of mid-point values: the coefficients used to weight the variations are the average of the arrival value and the starting value. The third approach is the use the mean of the $n$ ! possible decompositions.

Dietzenbacher and Los (1998) showed, in a numerical example, that the results of these three approaches are very similar. But they recommend using the third method, the mean value of all decompositions, because it shows the variability (or uncertainty) associated with each term, in addition to its mean value. Estimating variability ensures that the sign of the coefficient associated with each effect is robust - a necessary check, as Nagashima (2018) has pointed out. Therefore, we follow the recommendation of Dietzenbacher and Los (1998) and use the mean-value approach in this study.

This paper follows the recommendation of Dietzenbacher and Los (1998) and use the mean-value approach in this study. This approach looks at all possible permutations, and then takes for each driver the average of all its possible values. This methodology allows to show the minimum and maximum values, thus the range of uncertainties. It highlights whether the sign of a driver, or the ranking between two drivers, are robust to all possible decompositions.

\section{A.6 Uncertainty analysis}

The decomposition method we choose allows to estimate the uncertainty of the results obtained (cf. section 2.3). The variability associated with each factor is represented in the figure 6 . The most important uncertainties are found for the carbon intensity of production, the structure of production and the structure of consumption. On the contrary, there is low uncertainty associated with the effect of per capita wealth and population. For direct emissions from household, there is no uncertainty as they are not part of the SDA decomposition. Despite the observed uncertainty, the relative order and sign of the factors remain unchanged. In particular, the preponderance of carbon intensity drivers (decreasing emissions) and the wealth effect (increasing emissions) remains clear. 


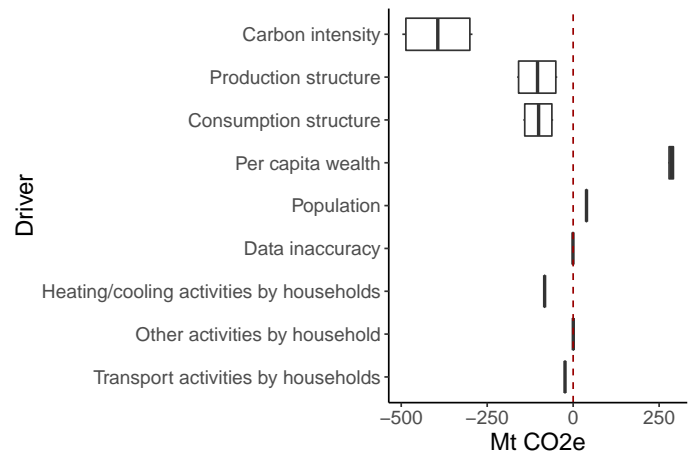

Figure 6: European GHG emissions drivers. The box plot indicates the uncertainty stemming from the choice of decomposition order.

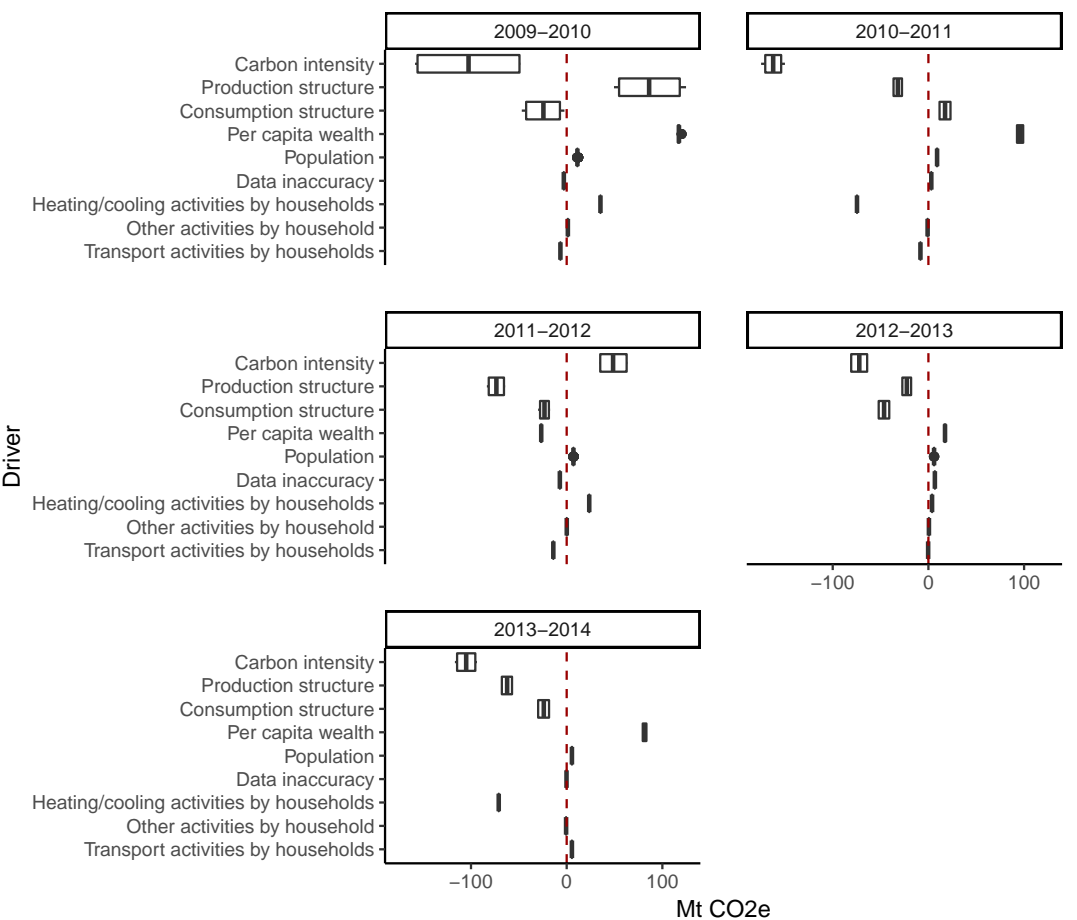

Figure 7: Variability of drivers for EU, for each year from 2009 to 2014, depending on the decomposition method. 


\section{A.7 Annual EU dynamics}

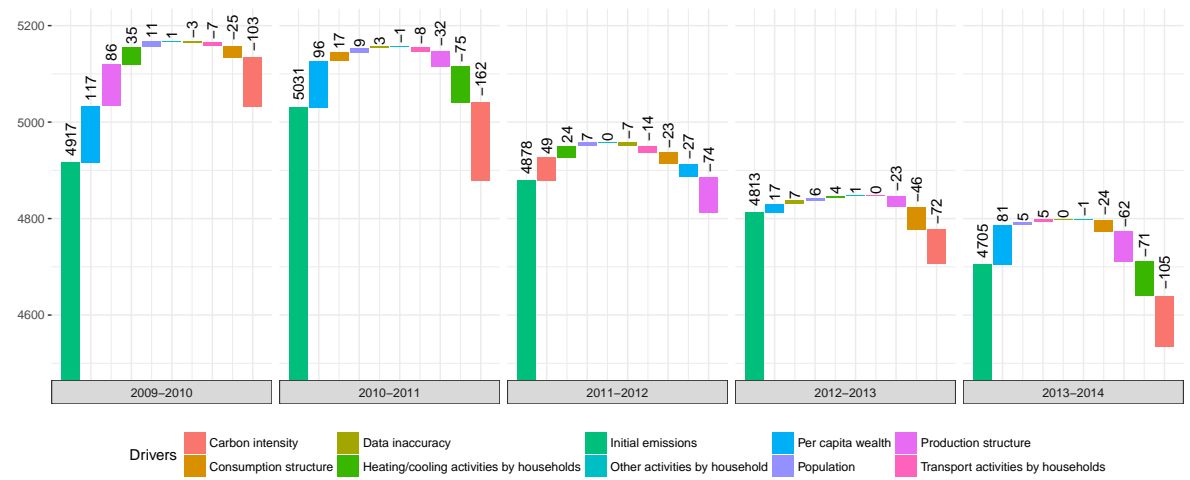

Figure 8: Annual decomposition of European GHG emission drivers, in million tonnes of $\mathrm{CO}_{2} \mathrm{e}$.

\section{A.8 Consumption structure}

To break down the consumption structure effect and show the contribution of each sector, we rewrite equation 7 and diagonalize the carbon intensity vector $\boldsymbol{c}$. The result of the right-hand equation is now a vector of industrial emissions, $\boldsymbol{g h} \boldsymbol{g}^{\text {ind }}$, whose term $i$ equals the emissions in sector $i$ :

$$
\boldsymbol{g h} \boldsymbol{g}^{i n d}=\widehat{\boldsymbol{c}} \cdot \boldsymbol{L} \cdot \boldsymbol{s} \cdot y \cdot p
$$

where $\widehat{ }$ is the diagonalization operator. Differentiating this equation, following the method explained in sections 2.3 and A.5, enables to compute the contribution of each sector. 


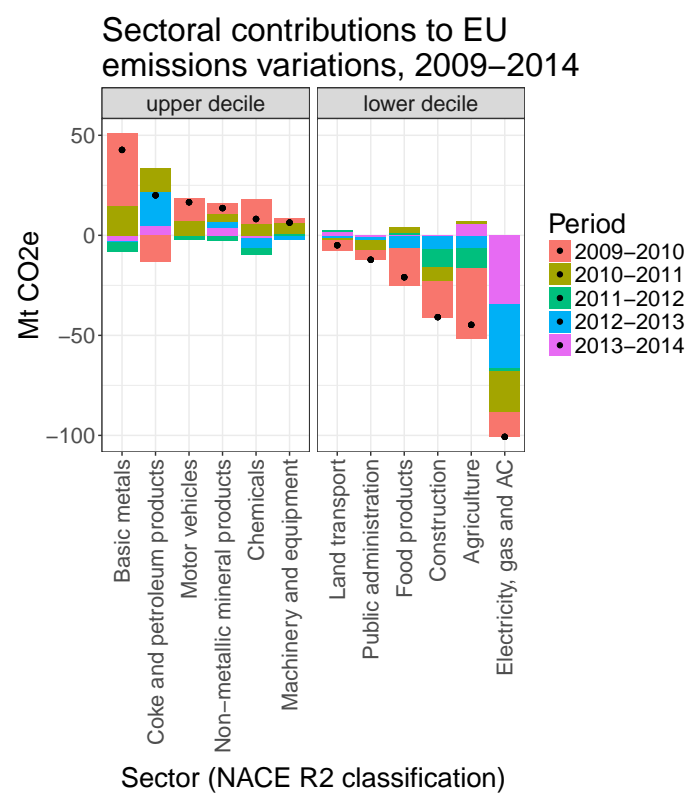

Figure 9: Main sectoral contributions to EU emissions variations, 2009-2014. The rectangles show the relative contributions, and the black dot indicates the net result. The contribution from all sectors is shown in figure 10 .

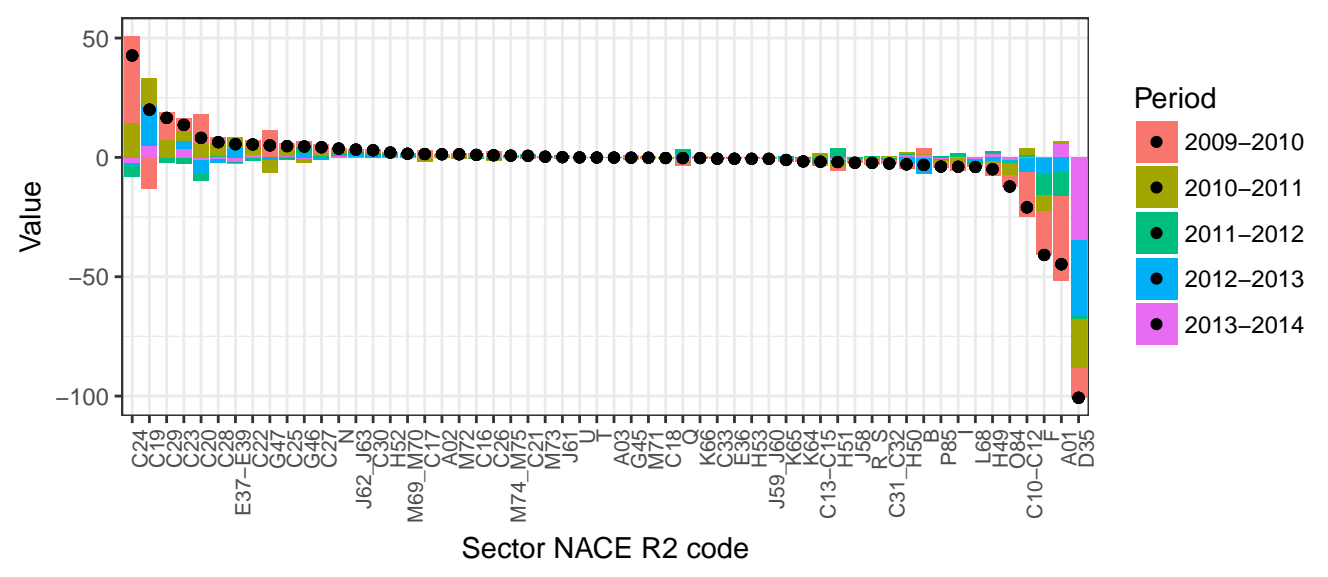

Figure 10: Sectoral contributions of the 56 sectors to EU emissions variations, 2009-2014. The code names are the ones used in the NACE R2 classification. More information can be found in Eurostat (2008). 


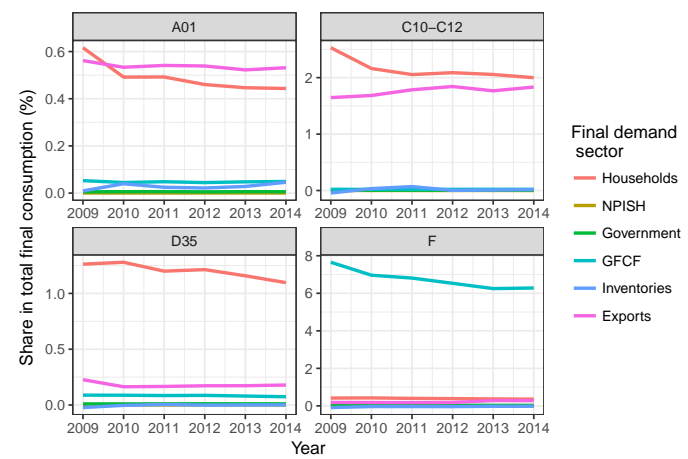

Figure 11: European final demand, split by its main components. NPISH is the acronym for Non-profit institutions serving households, and GFCF for Global Fixed Capital Formation.

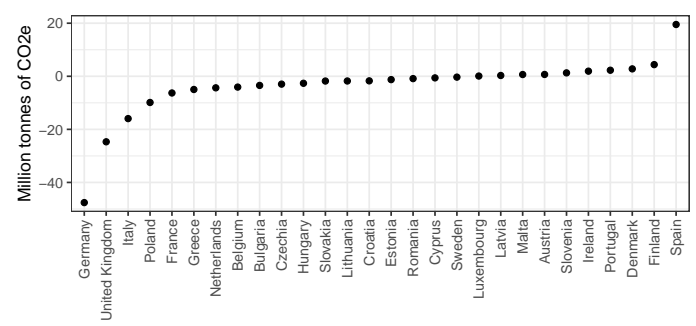

Figure 12: Impact of the consumption structure for each country

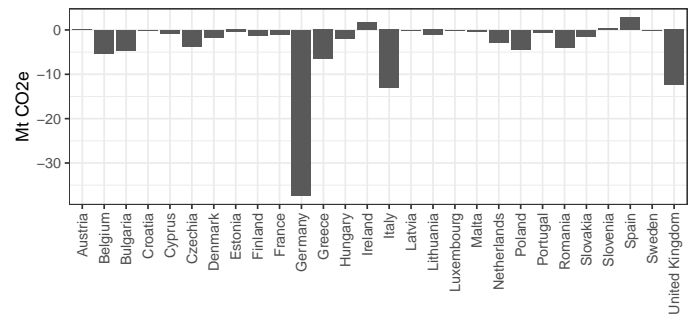

Figure 13: Impact of the consumption structure in the power sector for each country 


\section{A.9 Production structure}

Mathematically, the structural effect can be broken down by showing the matrix of intermediate consumption $\boldsymbol{A}$ and the matrix of Leontief $\boldsymbol{L}$, according to their values in the year of departure and the year of arrival (indicated respectively by indices 0 and 1):

$$
\Delta \boldsymbol{L}=\boldsymbol{L}^{1}\left(\boldsymbol{A}^{1}-\boldsymbol{A}^{0}\right) \boldsymbol{L}^{0}
$$

The consumption matrix $\boldsymbol{A}$ can then be decomposed between the total matrix $\boldsymbol{A}_{\boldsymbol{t}}$, which represents the technical requirements of the production function, and the intermediate import matrix $A_{m}$.

$$
\begin{gathered}
\Delta \boldsymbol{L}=\boldsymbol{L}^{1}\left[\left(\boldsymbol{A}_{t}^{1}-\boldsymbol{A}_{m}^{1}\right)-\left(\boldsymbol{A}_{t}^{0}-\boldsymbol{A}_{m}^{0}\right)\right] \boldsymbol{L}^{0} \\
\Delta \boldsymbol{L}=\boldsymbol{L}^{1}\left(\Delta \boldsymbol{A}_{t}\right) \boldsymbol{L}^{0}+\boldsymbol{L}^{1}\left(-\Delta \boldsymbol{A}_{m}\right) \boldsymbol{L}^{0}
\end{gathered}
$$

Although this methodology is indicated in Miller and Blair (2009), we have not seen it being used in other SDA studies of emissions.

In this additive form, the first term of the right-hand side reflects what we have called "technical change" in table 2. It represents changes in the input requirements to produce each good or service. All other things being equal, more input intensive production contributes to higher emissions. The second term indicates the contribution of changes in imports: an increase in imports tends to decrease domestic emissions.

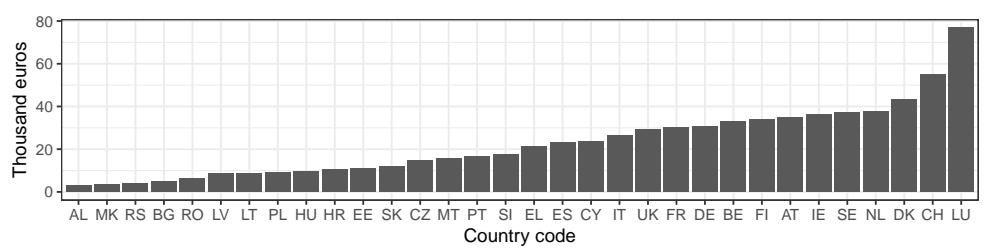

(a) GDP per capita in 2009

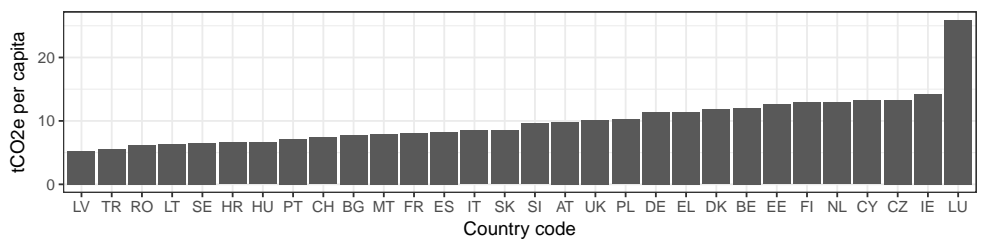

(b) Tonnes of $\mathrm{CO}_{2}$ e per capita in 2009

Figure 14: GDP and emissions per capita of European countries Source: Eurostat, databases sdg_08_10 and t2020_rd300 respectively. 


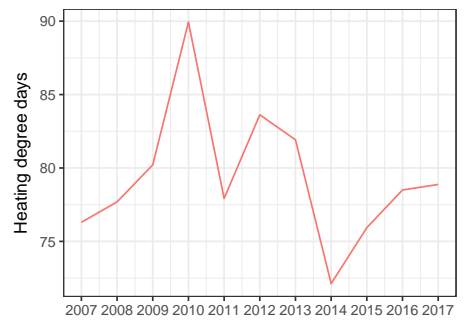

(a) Heating degree days in the EU, average of the 28 countries

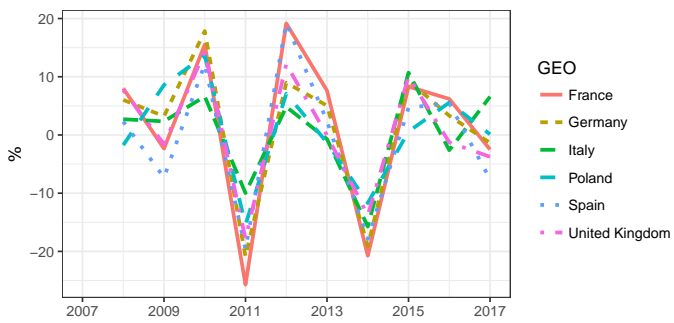

(b) Variation of heating degree days for large European economies

Figure 15: Variation of heating degree days in the EU and for European economies. Source: Eurostat, database nrg_chdd_a.

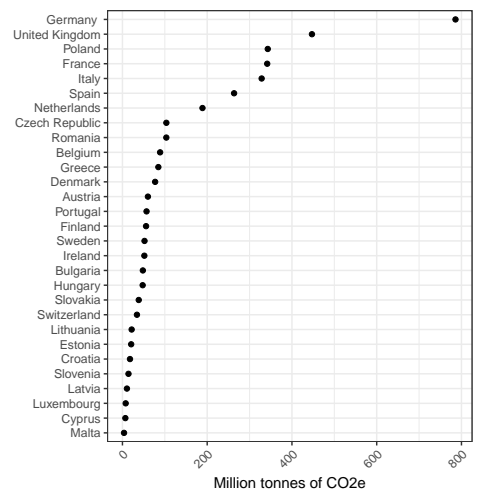

Figure 16: GHG emissions by country in 2014. The largest economies are also the largest emitters, which justifies focusing on them. 


\section{A.10 Country-by-country}

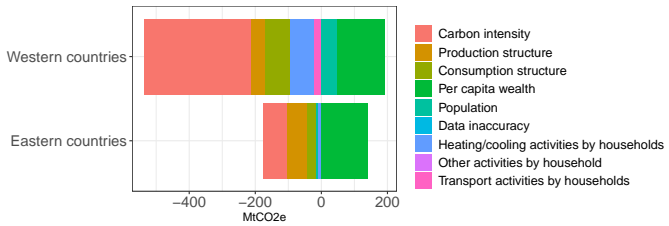

Figure 17: Emissions drivers of Western and Eastern EU countries

The group of Western countries considered here includes Austria, Belgium, Denmark, Germany, Finland, France, Ireland, Italy, Luxembourg, Malta, the Netherlands, Portugal, Spain, Sweden and the United Kingdom. The Eastern countries are made of the remaining EU countries. 